\title{
Crafting a Judicially Manageable Standard for Partisan Gerrymandering: Five Necessary Elements
}

\author{
Bernard Grofman
}

\begin{abstract}
Beginning with a definition of gerrymandering, and after a brief review of the evolution of the case law on partisan gerrymandering, I propose five necessary elements of a test for when partisan gerrymandering rises to the level of unconstitutionality: (a) a clear and severe injury involving a disparate impact on a political party that serves as the vehicle for the expression of particular ideas and values; (b) effects that can be expected to be durable; (c) effects that can be shown not to be explicable either by features of the partisan electoral geography that impact all plans, or by chance; (d) evidence that there exist one or more remedial plans that address the constitutional violation while also satisfying, on balance, all relevant constitutional and statutory criteria at least as well as the challenged plan; and (e) compelling direct or indirect evidence of invidious partisan intent. I link these five elements to recent Supreme Court and district court opinions about an appropriate standard for partisan gerrymandering.
\end{abstract}

Keywords: redistricting, partisan gerrymandering, voting rights, expert witness testimony, partisan bias, partisan asymmetry

\section{INTRODUCTION}

$\mathbf{S}$ OME OF THE MOST IMPORTANT DECISIONS the Supreme Court will be making in 2018 involve redistricting, including a potentially seminal decision on a set of lower court cases up on appeal that will determine whether the Supreme Court's previous holding that partisan gerrymandering is justiciable ${ }^{1}$ will actually have any teeth. Although

Bernard Grofman is the Jack W. Peltason Chair of Democracy Studies and Professor of Political Science at the University of California, Irvine. The views in this essay are solely those of the author, based on his own academic analyses, and do not reflect the views of any parties to previous cases in which he has been involved, nor those of any foundation, nor those of UC Irvine, nor those of any other organizations or interest group. However, in formulating his statistical conclusions, he has had valuable input from Professor Emeritus of Biostatistics, Samuel Merrill, III, and research assistance from Jonathan Cervas.
I will discuss opinions by recent trial courts in partisan gerrymandering challenges, I deliberately do not focus on the factual specifics of these cases, or the credibility of particular expert witness testimony; nor do I take a position as to whether the case facts and the expert witness testimony are such that the court reached a correct decision in the case. ${ }^{2}$ Instead, I examine the broader issues

\footnotetext{
${ }^{1}$ Davis v. Bandemer, 478 U.S. 109 (1986).

${ }^{2}$ There appears to be a near unanimous consensus among experts who have written on this topic that, for congressional districting, gerrymandering in the 2010 round was especially egregious in Michigan, North Carolina, Ohio, and Pennsylvania. There is also a strong but not unanimous consensus that Florida, Georgia, Indiana, Virginia and Wisconsin also constituted partisan gerrymanders, and some reasons to be suspicious in another half dozen or so states. As noted above, in this essay I will not address the accuracy of such expert views with respect to any particular plan, but instead examine metrics by means of which the degree of egregiousness of gerrymandering might be measured.
} 
of providing an empirically and jurisprudentially grounded test for unconstitutional partisan gerrymandering that fully addresses the concerns about judicial manageability raised by the Supreme Court in past cases.

While redistricting has potentially far-reaching implications for the partisan balance/partisan control in the U.S. House of Representatives and in a number of state legislatures, dealing with egregious partisan gerrymandering is not a partisan matter. Gerrymandering now benefits Republicans in more states than it benefits Democrats, but in the past the reverse has been true. ${ }^{3}$ Moreover, if we look at the partisan gerrymandering challenges presently (December 2017) before the Supreme Court, one from Wisconsin, ${ }^{4}$ one from Maryland, ${ }^{5}$ the first challenges a state legislative plan as a Republican-drawn partisan gerrymander, the second challenges a particular congressional district as part of a Democrat-drawn partisan gerrymander. In either case, it is the voters whose impact on electoral outcomes is minimized or canceled out and whose associational rights are violated who are the losers.

Egregious partisan gerrymandering discriminates against voters based upon their political views. Partisan gerrymandering done with the modern tools of sophisticated computer-based line drawing can "lock in" that discriminatory disparate impact for an entire decade, by creating districts that are entirely or almost entirely non-competitive. In such non-competitive districts, substantial changes in voter preference-even at the maximum magnitude we might reasonably expect when we examine constituency level data from previous electionswould lead to, at most, a few changes in partisan control at the district level, and perhaps none at all. Indeed, in some states, the existence of severely discriminatory gerrymandering, coupled with few or no competitive constituencies, would make (lopsided) partisan control of a legislature or a congressional delegation based on successful partisan gerrymandering impervious to change.

McGann et al. (2016) show that the potential for egregious partisan gerrymandering is greatest when you have unified partisan control of both branches of the legislature and of the governorship. The proportion of states with such unified control was very high in the 2010 round of redistricting but is now even higher. ${ }^{6}$ Thus, if there is no legal check on partisan gerrymandering, we have good reason to ex- pect that the level of egregious gerrymandering will be even worse in the 2020 round of redistricting than even the extraordinarily high level of partisan gerrymandering we saw in some states in their 2010 redistricting.

The central claim in this paper is that, from a social science perspective, we should define the concept of partisan gerrymandering in terms of five elements:

(a) a clear and severe injury involving a disparate impact on a political party that serves as the vehicle for the expression of particular ideas and values;

(b) effects that can be expected to be durable;

(c) effects that can be shown not to be explicable either by features of the partisan electoral geography that impact all plans, or by chance;

(d) evidence that there exist one or more remedial plans that address the constitutional violation while also satisfying, on balance, all relevant constitutional and statutory criteria at least as well as the challenged plan; and

(e) compelling direct or indirect evidence of (invidious) partisan intent.

In the remainder of this article I will focus on the first three of these elements. These three elements are derived from equal protection and First

${ }^{3}$ Because gerrymandering occurs at and needs to be addressed at a state level, the issue of net national effects is of little or no legal relevance to the cases now before courts. But we can nonetheless acknowledge the fact that in 2011-12, Republicans had unified control of many more states than did Democrats, 22 to 11 -which meant that many more states had gerrymandering advantaging Republicans than gerrymandering in a proDemocratic direction. In contrast, not only were gerrymanderers more constrained by concerns about possible lawsuits and politics less polarized, but in past decades pro-Republican districting in Republican-controlled states was more likely to be counter-balanced by pro-Democratic bias in states controlled by Democrats. McGann et al. (2016) make a compelling case that the partisan gerrymandering we see in 2010 redistricting is, qualitatively as well as quantitatively, a different level from what we have seen in previous decades. They find (p. 97) that the level of partisan bias in the 2010 districting round was approximately three times that in the 2000 round.

${ }^{4}$ Whitford v. Gill, No. 15-cv-421-bbc, 2016 WL 6837229 (W.D. Wisc. filed Nov. 21, 2016).

${ }^{5}$ Benisek v. Lamone, Civil No. JKB-13-3233 (D. Md. filed Aug. 24, 2017).

${ }^{6}$ The imbalance in unified control of states has grown to a more than 4-1 Republican advantage after the 2016 elections. "State Government Trifectas," Ballotpedia, <https://ballotpedia.org/ State_government_trifectas $>$. 
Amendment principles, ${ }^{7}$ and the social sciences offer reliable, transparent, and manageable tools for measuring each. Because each of the elements above reflects a different concept, it is important to recognize that no one number tells it all. As for the need to demonstrate the potential for a remedy to the (claimed or demonstrated) constitutional violation, without a remedy it is hard to see how there can be a cause of action. And, to the extent that partisan intent needs to be proved, there is well-established jurisprudence in the racial gerrymandering cases and in other civil rights domains that can be adapted. ${ }^{8}$ Moreover, when (long term) consequences can be shown to be foreseeable, intent can be indirectly addressed via statistical evidence about the improbability that observed outcomes can be attributed to chance. Accordingly, my discussion of the intent element will be brief.

The approach to defining and measuring unconstitutional partisan gerrymandering given above is designed to explicitly take into account the concerns expressed by Supreme Court justices in cases such as Bandemer, Vieth, and $L U L A C^{9}$ about the need to show that the disparate effects of districting are likely to be durable as well as severe, and that they cannot be explained simply by electoral geography or by chance. These latter two elements (the second and third of the five elements above) can be measured by social science tools that were not available (or at least not offered by plaintiffs) in the previous partisan gerrymandering cases that made it to the Supreme Court. ${ }^{10}$ By offering (a) a way to determine whether gerrymandering effects could be expected to last a decade, and (b) a statistical test to rule out claims that the observed partisan bias is due simply to chance or to the geographic distribution of partisan voting strength, these new tools address two of the major concerns that led to various justices questioning the potential for a manageable standard for partisan gerrymandering. These new tools can be combined with measures of partisan bias/partisan asymmetry that five justices in LULAC previously saw as a key element of any standard for unconstitutional partisan gerrymandering, to form the bases for a multi-pronged legal standard for when disparate impact rises to the level of unconstitutionality.

In the next section, after briefly reviewing the history of partisan gerrymandering litigation (ca December 2017), and offering a definition of gerrymandering, I will address how the five elements of a test for unconstitutional partisan gerryman- dering identified above can best be defined and measured. The metrics I propose are ones explicitly or implicitly referenced in the majority opinions in Whitford v. Gill ${ }^{11}$ and Common Cause v. Rucho, ${ }^{12}$ arguably the two most important recent trial court decisions about partisan gerrymandering. Then I will consider some other legal issues, most importantly the question of whether the metrics I propose and the tools to measure them allow for the creation of a judicially manageable standard for unconstitutional partisan gerrymandering. I argue that such a standard can be defined in terms of a set of necessary conditions whose components can be directly and reliably measured. In this way, the standard will allow for judicial manageability both in restricting the set of cases that could be litigated and in terms of the ability of courts to assess the relevant expert witness evidence.

${ }^{7}$ See, e.g., Vieth, 541 U.S. 267, 314 (2004) (opinion of Kennedy, J.) ("First Amendment concerns arise where a State enacts a law that has the purpose and effect of subjecting a group of voters or their party to disfavored treatment by reason of their views. In the context of partisan gerrymandering, that means ... where an apportionment has the purpose and effect of burdening a group of voters' representational rights."); Bandemer, 478 U.S. at 124 ("[E]ach political group in a State should have the same chance to elect representatives of its choice as any other political group."). Invidious partisan gerrymandering occurs when a political party intentionally redraws district lines to give itself a durable electoral advantage over the party out of power-usually by "packing" voters who affiliate with the opposing party into a few safe districts, or by "cracking" them across multiple districts to dilute their voting power. See Bandemer, 478 U.S. at 117 n.6 (explaining "the familiar techniques of political gerrymandering"). In so doing, an unconstitutional partisan gerrymander can discriminate against voters in their representational rights because of their views and political associations in a way that cannot realistically be ameliorated through the ordinary electoral process.

${ }^{8}$ At what point, if any, the legal burden shifts to defendants to show that the challenged plan's objectionable features can be justified by legitimate (and compelling) state purposes is a legal matter beyond the scope of this essay.

${ }^{9}$ Davis v. Bandemer, 478 U.S. 109 (1986); LULAC v. Perry, 548 U.S. 399 (2006); Vieth v. Jubelirer, 541 U.S. 267 (2004).

${ }^{10}$ Davis v. Bandemer, 478 U.S. 109 (1986); Vieth v. Jubelirer, 541 U.S. 267 (2004); and LULAC v. Perry, 548 U.S. 399 (2006).

${ }^{11}$ Whitford v. Gill, No. 15-cv-421-bbc, 2016 WL 6837229 (W.D. Wisc. filed Nov. 21, 2016), about Wisconsin legislative districting.

${ }^{12}$ Common Cause v. Rucho, No. 1:16-CV-1164 (M.D. N.C. filed Jan. 9, 2018). 


\section{DEFINING AND MEASURING PARTISAN GERRYMANDERING}

\section{A brief history of legal challenges to partisan gerrymandering}

Since 1986, when Davis v. Bandemer declared partisan gerrymandering to be justiciable and egregious gerrymandering to be potentially unconstitutional, there have been three decades of Supreme Court and lower court decisions directly responding to allegations of partisan gerrymandering. But, as of December 2017, there had never yet been a Supreme Court decision striking down a plan (or one or more districts) as an unconstitutional partisan gerrymander. In the cases that made it up for Supreme Court review, the Court majority asserted that it had failed to identify manageable standards to decide when a plan rises to the level of an unconstitutional partisan gerrymander. In light of these negative decisions, it became the common wisdom among the legislators drawing the lines in the redistricting of the current decade that they could do what they liked regarding partisan gerrymandering as long as they satisfied one person, one vote standards and did not reduce the electoral success chances of African Americans or other protected racial and ethnic groups. ${ }^{13}$ As a result of the Supreme Court's complete abdication of responsibility, the 2010 round saw partisan gerrymandering run amok in some states. Indeed, we even saw some redistricting authorities boasting about the fact that their plan was intended as a partisan gerrymander as a defense to claims that some districts in the plan had race as their preponderant motive. ${ }^{14}$

In the past few years there are some signs that the state of the case law about partisan gerrymandering might be changing. In the 2010 redistricting round, Florida plans were struck down on state law grounds, ${ }^{15}$ and federal courts have now

\footnotetext{
${ }^{13}$ Some academic authors (e.g., Grofman and King 2007) took $L U L A C$ to be an open invitation to lower courts to respond to the request of Justices Souter and Ginsburg in LULAC that "further attention ... be devoted to the administrability of such a criterion [partisan bias] at all levels of redistricting and its review." However, after 25 years in which no plan had ever been struck down as a partisan gerrymander despite the Court's holding that partisan gerrymandering was justiciable, most redistricting authorities in the 2010 round of redistricting saw LULAC as simply demonstrating that partisan gerrymandering claims were a dead letter, destined to fail. In fact, many lower courts confronted with a partisan gerrymandering challenge postLULAC simply refused to consider the claim and asserted that, until the Supreme Court provided a standard to adjudicate the claim, their hands were tied. The decision in LULAC could also be seen as an invitation to litigants to develop a more sophisticated and multi-componented test for unconstitutional gerrymandering that incorporated but was not limited to partisan bias. And that is indeed what has happened, but not until rather late in the 2010 redistricting period (see below).

14 "After the three-judge court in Harris v. McCrory, $2016 \mathrm{WL}$ 3129213 (M.D. N.C. June 2, 2016), found the challenged North Carolina congressional districts constituted a racial gerrymander, "the North Carolina legislature drew new district lines, expressly eschewing reliance on any racial data and declaring that they were engaged in a partisan gerrymander" (Hasen 2018 forthcoming, draft p. 16). "As [North Carolina] Representative Lewis stated, 'I acknowledge freely that this would be a political gerrymander... [W] e want to make clear that we ... are going to use political data in drawing this map. It is to gain partisan advantage on the map. I want that criteria to be clearly stated and understood.... I'm making clear that our intent is to use-is to use the political data we have to our partisan advantage." Harris v. McCrory, 16-666 (statement of jurisdiction filed Aug. 3, 2016), <https://www.supremecourt.gov/search.aspx?

filename=/docketfiles/16-166.htm >, cited in Hasen (2018 forthcoming). As Hasen notes, the state drew 10 of 13 congressional districts to favor Republicans, in a state where party registration is roughly even between Democrats and Republicans.

${ }^{15}$ While, until Whitford, federal courts after Davis v. Bandemer had never found a single-member district plan to be an unconstitutional partisan gerrymander, in 2015 the Florida Supreme court invalidated a Florida congressional map as a partisan gerrymander (League of Women Voters of Florida v. Detzner, 172 So. 3d 363 (Fla. 2015)). As a result of the ruling, eight congressional districts were ordered to be redrawn, with spillover effects on other districts. An earlier legislatively drawn remedy map was rejected as failing to fully address the constitutional violations. Because the legislature was unable to agree on a new map, a court-drawn plan was used in 2016, and one congressional seat changed hands. The Florida decision was based on state rather than federal law, and the provisions of Florida's constitution relied upon in the case were very specific ones, added rather recently by a citizen initiative, with language not duplicated in most other state constitutions (language in Ohio's constitution put there in 2015 via a citizen initiative is a partial exception). While this particularity of the Florida case led me to believe that state law-based challenges to partisan gerrymandering were unlikely to be successful, as of January 22, 2018, the Pennsylvania state law challenge was successful. Moreover, some elements of the Florida case may also prove adaptable to the federal context, especially with respect to the standard for determining intent, the need for burden-shifting to defendants to justify the plan if a clear violation is found, the question of whether an appropriate remedy involves overturning a whole plan or only particular districts, and the amount of deference due the legislature in the remedial phase once a violation is found.
} 
found plans in Wisconsin ${ }^{16}$ and North Carolina ${ }^{17}$ to be unconstitutional partisan gerrymanders on federal law grounds. However, another federal court found against a partisan gerrymandering challenge, ${ }^{18}$ and a fourth stayed proceedings challenging a Maryland congressional district as an unconstitutional partisan gerrymander until the merits of the Wisconsin challenge had been resolved by the Supreme Court. ${ }^{19}$ As of December 2017, the first of these cases, Whitford v, Gill heard sub nom. Gillv. Whitford, a challenge to a legislative plan, along with the Maryland case involving a challenge to a single congressional district, are up on appeal to the Supreme Court, with the Wisconsin case already having had oral argument in 2017. There also has been a challenge to the Pennsylvania congressional plan dismissed after trial by a federal court by a $2-1$ vote in January $2018 .^{20}$ The North Carolina and
${ }^{16}$ Whitford v. Gill, No. 15-cv-421-bbc, 2016 WL 6837229 (W.D. Wisc. filed Nov. 21, 2016), about Wisconsin legislative districting.

${ }^{17}$ Common Cause v. Rucho, No. 1:16-CV-1164 (M.D. N.C. filed Jan. 9, 2018).

${ }^{18}$ Agre v. Wolf, Case 2:17-cv-04392-MMB, Document 211 at p. 3 (E.D. Pa. filed Jan. 10, 2018). This Pennsylvania challenge was brought under the Elections Clause of Article I of the United States Constitution. The majority opinion referred to the challenge as a "novel legal claim" and rejected the claim.

Plaintiffs' ambitious theory suffers from three fatal flaws. First, the Framers provided a check on state power within the text of the Elections Clause, but it is a political one-action by Congress. The language and history of the Clause suggest no direct role for the courts in regulating state conduct under the Elections Clause. Second, the Elections Clause offers no judicially enforceable limit on political considerations in redistricting. Plaintiffs' partisan blindness theory was long ago rejected by the Supreme Court, and for good reason. The task of prescribing election regulations was given, in the first instance, to political actors who make decisions for political reasons. Plaintiffs ignore this reality. In fact, they ask the Court to enforce the supposed constitutional command by requiring the Commonwealth of Pennsylvania to develop a new process that will somehow sanitize redistricting by removing political influence. Courts cannot mandate new processes for creating election regulations. The Elections Clause leaves that to state legislatures and to Congress-bodies directly accountable to the people. Third, Plaintiffs' Elections Clause claim is an unjustifiable attempt to skirt existing Supreme Court precedent. Partisan gerrymandering claims under the First Amendment and/or Equal Protection Clause are justiciable, but a majority of justices have yet to agree on a standard. Despite the lack of agreement, the justices favoring justiciability uniformly acknowledge that the courts should not assume a primary role in redistricting. Out of concern for a healthy separation from this most political of matters, the justices have proposed high bars for judicial intervention. Contrary to that concern, Plaintiffs offer an Elections Clause theory that invites expansive judicial involvement. Plaintiffs suggest that the Elections Clause offers an easily manageable standard. What they really mean is that it offers a lower bar-an easy path to judicial intervention. (with internal citations omitted)

However, the Rucho court (slip opinion at 175-180) takes a much more expansive view of the scope of the Elections Clause and finds that it, too, was violated in North Carolina's congressional redistricting.

${ }^{19}$ Benisek v. Lamone, Civil No. JKB-13-3233 (D. Md. filed Aug. 24, 2017). The Benisek challenge is distinct from that in the other partisan gerrymandering challenges in three ways. First, it challenges only a single district, not an entire plan; second, it relies entirely on First Amendment grounds; and third, it argues, in effect, that all that is needed under the First Amendment (as opposed to the Fourteenth Amendment) is evidence of intent to achieve illegitimate partisan ends by changing the partisan control of a district and evidence of success in that endeavor. In the predecessor case to Benisek, Shapiro v. McManus (203 F. Supp. 3d 579 (D. Md. 2016)), the Court specified a First Amendment test for partisan gerrymandering in the form of proof of the three elements of intent, injury, and causation.

When applying First Amendment jurisprudence to redistricting, we conclude that, to state a claim, the plaintiff must allege that those responsible for the map redrew the lines of his district with the specific intent to impose a burden on him and similarly situated citizens because of how they voted or the political party with which they were affiliated. In the context of redistricting, this burden is the injury that usually takes the form of vote dilution. But vote dilution is a matter of degree, and a de minimis amount of vote dilution, even if intentionally imposed, may not result in a sufficiently adverse effect on the exercise of First Amendment rights to constitute a cognizable injury. Instead, to establish the injury element of a retaliation claim, the plaintiff must show that the challenged map diluted the votes of the targeted citizens to such a degree that it resulted in a tangible and concrete adverse effect. In other words, the vote dilution must make some practical difference. Finally, the plaintiff must allege causation - that, absent the mapmakers' intent to burden a particular group of voters by reason of their views, the concrete adverse impact would not have occurred.

${ }^{20}$ Agre v. Wolf, Case 2:17-cv-04392, 04392-MMB (E.D. Pa. filed Jan. 10, 2018). 
Pennsylvania federal cases are also likely to be appealed to the Supreme Court, and there is a Texas partisan gerrymandering challenge that, when a final order is issued at the lower level, will certainly go up on appeal. Moreover, in a Pennsylvania congressional partisan gerrymandering challenge brought on state law grounds, in which a trial magistrate made findings of fact and a recommendation that the existing plan be upheld, ${ }^{21}$ the appeal to the Pennsylvania Supreme Court resulted, on January 22, 2018, in a victory for the plaintiffs in a 4-3 decision. ${ }^{22}$

In looking to the future of partisan gerrymandering, the two most important legal decisions ${ }^{23}$ since Bandemer to date are, arguably, the district court opinions in Whitford, about Wisconsin legislative plans, and Common Cause v. Rucho, about North Carolina congressional districting, because plaintiffs prevailed in each of these cases and each opinion offers a viable theory of partisan gerrymandering and standards that could be adopted by the U.S. Supreme Court. ${ }^{24}$ The legal standards proposed in each case to resolve partisan gerrymandering challenges are very similar to one another.

Both the Wisconsin and the North Carolina opinions follow up on a suggestion of Justice Kennedy in Vieth v. Jubelirer ${ }^{25}$ to consider partisan gerrymandering as potentially violating First Amendment associational rights in addition to raising equal protection issues under the Fourteenth Amendment. Both recognize that a defense to what would otherwise be evidence of unconstitutional partisan gerrymandering can be based on a claim that the result followed from a narrowly tailored and compelling legitimate state purpose. Both also directly address previous Supreme Court concerns about judicially manageable standards. In particular, they address issues about measuring the severity of the disparate effects, assessing the durability of effects, ruling out the possibility that effects can be attributed to geography or chance, and avoiding judgments based on evidence from, at most, a single election under the challenged plan. Moreover, in each, there is expert witness testimony that the judges draw upon in addressing each of these concerns. Both also look closely at issues of intent, including consideration of the process by which the plan was created and passed and geographic features of the plan that grossly violate traditional districting criteria.

In both cases the distinction between First Amendment and Fourteenth Amendment claims appears to be more a legal distinction about how to frame constitutional bases of action than a differ- ence in how courts should go about looking for a violation of those rights.

In Whitford, for example, the court majority asserted that "the First Amendment and the Equal Protection clause prohibit a redistricting scheme which (1) is intended to place a severe impediment on the effectiveness of the votes of individual citizens on the basis of their political affiliation, (2) has that effect, and (3) cannot be justified on other, legitimate legislative grounds." The Whitford court majority found: "The plaintiffs have established ... that the defendants intended and accomplished an entrenchment of the Republican Party likely to endure for the entire decennial period. They did so when the legitimate redistricting considerations neither required nor warranted the implementation of such a plan. "

In Common Cause v. Rucho, the majority offered a three-pronged test requiring plaintiffs to prove: "(1) that the challenged districting plan was intended to favor or disfavor individuals or entities that support a particular candidate or political party, (2) that the districting plan burdened the political speech or associational rights of such individuals or entities, and (3) that a causal relationship existed between the

${ }^{21}$ League of Women Voters v. Pennsylvania, No. 261M.D.2017 (Pa. Commw. 2017).

${ }^{22}$ As of January 22, 2018, however, there was not an opinion in the case laying down the grounds for the ruling. The legislature is being given the opportunity to offer a remedial plan satisfying good government standards under a very tight timeline. It is possible that the decision in this case will be appealed to the federal courts, though the grounds for such an appeal are not clear.

${ }^{23}$ While the emphasis in this essay in on legal routes to combating gerrymandering, an alternative route is to take redistricting authority away from the state and put it into the hands of a redistricting commission. This route was taken in California, and there is widespread but not universal agreement that the initiative led to a genuinely non-partisan redistricting in the first decade that there was a commission-drawn plan used in the state. The Commission's redistricting map was oriented toward good government concerns, with substantial public input, and the Commission had a complex set of procedures involving a tripartite rather than merely bipartite form of decision making. However, this is a route that, for all practical purposes, is available only in states that allow statewide initiatives, and so its potential impact is limited. Moreover, not all redistricting commissions operate in nearly as neutral or efficient a fashion as that in California, and the membership of some commissions is little more than a disguised form of partisan control (see, e.g., the discussion in McDonald 2004, and Miller and Grofman 2011).

${ }^{24}$ As noted earlier, Whitford is the first time since the trial court decision in Bandemer v. Davis - a decision reversed in Davis $v$. Bandemer - that a federal court has held a single-member district plan to be an unconstitutional partisan gerrymander.

${ }^{25} 541$ U.S. 267 (2004). 
governmental actor's discriminatory motivation and the First Amendment burden imposed by the districting plan." It held that:

Partisan gerrymandering runs contrary to both the structure of the republican form of government embodied in the Constitution and fundamental individual rights preserved by the Bill of Rights.... $[\mathrm{P}]$ artisan gerrymandering of congressional districts constitutes a structural violation because it insulates Representatives from having to respond to the popular will, and instead renders them responsive to state legislatures or political factions thereof.

\section{It found that:}

Rather than seeking to advance any democratic or constitutional interest, the state legislator responsible for drawing the 2016 Plan said he drew the map to advantage Republican candidates because he "think[s] electing Republicans is better than electing Democrats" (Ex. 1016, at 34:21-23). But that is not a choice the Constitution allows legislative map drawers to make. Rather, "the core principle of [our] republican government [is] that the voters should choose their representatives, not the other way around." Ariz. State Leg., 135 S. Ct. at 2677 (internal quotation marks omitted).

However, there does appear to be one interesting difference between the two types of claims. The Rucho majority held that because "the First Amendment harms attributable to partisan gerrymandering are analogous to one-person, one-vote claims and are not district specific, we conclude that partisan gerrymandering claims under the First Amendment need not be asserted on a district-by-district basis." 26 This is important because some cases, such as Benisek, offer a challenge limited to specific districts rather than to a plan as a whole, and the issue of whether or not partisan gerrymandering challenges may offer statewide evidence of effect is one of the issues at dispute in these cases. My own view on this point is quite clear: in line with the definition of gerrymandering given above, partisan gerrymandering claims are inherently statewide, though it may often be the case that the necessary remedies are district-specific. As the Rucho court noted about North Carolina, "in drawing the 2016 Plan, the General Assembly sought to achieve a statewide partisan effect." 27

Among redistricting experts, it is matter of close to unanimous consensus that, if the Supreme Court fails to draw on the lower court opinions in Whitford v. Gill and Common Cause v. Rucho to specify a manageable standard, that failure spells a finish to the potential for legal action by federal courts to cure unconstitutional gerrymandering in this round of redistricting. But worse, such a failure would also have a profound effect on the next decade's redistricting in unleashing still further unchecked instances of "partisan lust." 28

There are, however, several reasons why Whitford and Rucho have the potential to be "gamechangers." First, the expert witness testimony in these cases offers new tools for assessing the magnitude and durability of gerrymandering that are responsive to previous Supreme Court concerns about manageability. As we demonstrate later, these tools were not available (or not offered) in previous partisan gerrymandering challenges that made their way to the Supreme Court. Second, the cases spell out new legal theories, including ones based on First Amendment jurisprudence. Third, the evidence relied on in Whitford includes actual outcomes in three elections. Thus, the decision about gerrymandering effects is not complicated by the issue of the degree of predictability of future elections under a new plan for which the court does not yet have previous electoral outcomes as a basis for assessment.

\section{Defining a gerrymander}

What is gerrymandering? That is a deceptively simple question, but one which must be answered before we can begin to even think about unconstitutional partisan gerrymandering. The answer I give-one that is consistent with the views of

\footnotetext{
${ }^{26}$ Common Cause v. Rucho, No. 1:16-CV-1164, slip op. at 35 (M.D. N.C. filed Jan. 9, 2018).

${ }^{27}$ Id. at 37.

${ }^{28}$ These were the views expressed by panelists in presentations at the Common Cause Conference on Redistricting Reform, held at the Duke University School of Public Policy, March $2-3,2017$, attended by the author. If the direct route to attacking partisan gerrymandering is cut off, then that will leave only indirect routes such as attacking plans with partisan effects as discriminatorily making use of population discrepancies or as making race a predominant motive. Such indirect lines of attack are very limited in their potential applicability. Moreover, it is extremely unlikely, even if such indirect attacks are successful, that the specific remedies imposed will actually cure the partisan gerrymandering that motivated the litigation but which was not actually the subject of the litigation.
} 
most present-day social scientists who are specialists on districting is that:

Gerrymandering occurs when a districting plan creates a disparate treatment of the vote share of the minority and majority voting blocs in a way that penalizes the minority in its ability to translate its voting support into seats compared to what we might expect from a plan drawn on the basis of neutral principles. ${ }^{29}$

Thus, gerrymandering has two critical elements. It requires disparate impact, and it is to be measured relative to a baseline of a plan drawn on the basis of neutral principles. The definition above corrects an important misapprehension of the nature of gerrymandering which was once frequently asserted about legislatures using single-seat plurality districts electing candidates by plurality; namely, the misleading claim that, in such legislatures, gerrymandering is merely a synonym for districting. ${ }^{30}$

\section{Defining unconstitutional partisan gerrymandering: Five key elements}

The definition given in the section above is a definition of gerrymandering; it is not a definition of what constitutes unconstitutional gerrymandering. Not all disparate impact rises to the level of unconstitutionality. For gerrymandering to rise to the level of unconstitutionality in terms of the five elements of my proposed test, not only must it be shown that there is a disparate impact, but the disparate impact must be shown to be substantial, and highly durable, and with effects that cannot be explained by the nature of the electoral geography or by chance, and with effects that can be shown to have been intended. ${ }^{31}$ Moreover, of course, there must be one or more feasible remedies for the unconstitutional disparate impact found.

\section{Measuring disparate impact}

The first element, partisan asymmetry, is based on the idea that a citizen's representational rights must not turn on the party with which he chooses to affiliate. It looks to see if there is a tangible and concrete injury in the form of disparate impact that could be the basis for a claim of unconstitutional partisan gerrymandering. In short, it is a standard of "neutral" treatment. This metric nei- ther assumes nor requires that a political party is entitled to any particular election outcome. Rather, partisan symmetry requires only that if we were to "switch the names of the parties that received particular vote outcomes, the seat outcomes would also switch." 32 Unlike a claim that a party is entitled to a specified outcome, such as a number of seats proportionate to its vote share, an asymmetry standard requires only that the parties and their supporters receive equal treatment-that they have equal opportunity to translate their votes into representation.

For example, imagine that the "Democratic Party receives an average of $55 \%$ of the vote totals in a state's legislative district elections and, because of ${ }^{29} \mathrm{By}$ the majority bloc I mean the party that is in control of the
districting process.
${ }^{30}$ The paradigmatic claim of this supposed equivalence is found
a 1968 book, Democratic Representation: Reapportionment in Law and Politics (Oxford University Press) by Robert Dixon, arguably America's then leading expert on redistricting. He asserted: "To be brutally frank, whether or not there is a gerrymander in design, there normally will be some gerrymandering in result, as a concomitant of all district systems of legislative elections.... In a functional sense it thus may be said that districting is gerrymandering." Knowing what we know now, especially in terms of research both conceptual and empirical done over the past decade or so, the statement above is misleading. Unfortunately, the academic literature on districting has not always recognized this point. Indeed, I should be honest in noting that in my earlier writings, the present author, too, has uncritically quoted Dixon's assertion above, especially in verbal presentations. Still, I believe it is accurate to say that few, if any, knowledgeable social scientists today would endorse Dixon's views from nearly five decades ago. Dixon wrote at a time when the statistical properties of seats-votes relationships for plurality districts were not well understood, e.g., he wrote prior to Tufte (1973) and the extensive literature that has followed. As a guide to understanding the conditions needed to determine the existence of gerrymandering, and especially whether or not that level of gerrymandering rises to the level of unconstitutionality, this conflating of districting with gerrymandering cannot be the basis of a constitutional standard. It fails to provide a truly functional test of the partisan (or racial, or incumbency protecting) consequences of an adopted plan that distinguishes these consequences in terms of disparate impact from what might have been expected from a plan drawn according to neutral principles.

${ }^{31}$ While the term "natural gerrymandering" has been used for gerrymandering consequences whose effects were not intended, it seems sensible to view unconstitutional partisan gerrymandering as necessarily involving intent, though this view is not shared by all social science redistricting experts and will ultimately have to be resolved by the Supreme Court. We have placed intent as the last of the five elements because it may be demonstrated indirectly from some of the earlier elements.

${ }^{32}$ Grofman and King (2007). 
the way the district lines were drawn, it wins $70 \%$ of the legislative seats in that state." ${ }^{33}$ This "one piece of evidence alone" says nothing about whether any voters have been treated differently based on their political views. ${ }^{34}$ That turns on whether the result would be different were the shoe on the other foot: if the Republican Party would also have received $70 \%$ of the seats in an election in which it garnered an average of $55 \%$ of the vote, then there is no disparate treatment. ${ }^{35}$

In fact, mere disproportionality between vote share and seat share does not evidence a partisan gerrymander. The political science is clear: winner-takeall, single-member district elections-elections in which a plurality of the votes wins the district's seat-do not produce proportionate results, because "in practice they normally give a 'bonus' of varying sizes (above proportionality) in seats to the party that wins a majority of the votes across a state." 36

The scholarly literature has overwhelmingly supported the concept of partisan asymmetry as the basis for a definition of disparate partisan impact in electoral systems since at least the late 1980 s. $^{37}$ Measures of asymmetry not only reliably establish whether a map provides an advantage to one party's voters over another, they also identify the degree of the advantage. Social scientists have developed multiple measures of partisan asymmetry that courts and litigants can readily apply.

One straightforward measure of partisan asymmetry is partisan bias. It "refers to the degree to which a [map] deviates from partisan symmetry." (Grofman and King 2007, 10). For example, if Party A would receive $60 \%$ of the seats with $50 \%$ of the statewide vote, but Party B would receive only $40 \%$ of the seats with $50 \%$ of the statewide vote, there is a partisan bias of 20 percentage points favoring Party A. By multiplying the amount of bias by the number of seats in the map, we can calculate approximately how many seats were impacted-e.g., assuming 100 legislative seats, a 20-point bias would mean the disadvantaged party and its members lost the opportunity to capture 20 seats. $^{38}$

Where elections have occurred under the challenged map, one way to evaluate whether the parties have like opportunity to translate seats into votes is to adjust their respective vote shares district by district to see how they would fare if the tables were turned. Imagine Party A won $70 \%$ of the seats after garnering $53 \%$ of the statewide vote, and Party B received $30 \%$ of the seats with $47 \%$ of the statewide vote. To simulate the seat shares if instead Party B won 53\% of the statewide vote and Party A won $47 \%$ of the statewide vote, simply add six percentage points $(53 \%-47 \%)$ to Party B's vote share in each district and subtract six percentage points from Party A's vote share in each district. Then tally up how many seats Party B would have won, and calculate its percentage of total seats. If Party B, now simulated to receive about $53 \%$ of the

${ }^{33} I d$.
${ }^{34} I d$.
${ }^{35}$ In a system of proportional representation (used in many Euro-
pean countries), seats are awarded in proportion to overall vote
share-i.e., $55 \%$ of the statewide votes would garner about
$55 \%$ of the legislative seats. "Proportional Representation,"
Encyclopedia Britannica (2013 ed.), <https://tinyurl.com/
y6welcph>. As the above example illustrates, the symme-
try standard requires no such result. The symmetry standard
"does not require proportionality but only that the dis-
proportionality be the same for both parties." McGann et al.
(2016, 65-66).
${ }^{36}$ Grofman and King (2007, 22); see also Wang (2016b, 368$374)$.

${ }^{37}$ See Grofman and King (2007, at p. 6 and footnotes 29-30). A number of experts in the field of redistricting recently filed amicus briefs in Gill v. Whitford, No. 16-1161 (U.S. 2017). Almost all take the view that partisan asymmetry is a key element of any partisan-gerrymandering claim (e.g., Br. of Heather Gerken et al., at 15-17; Br. of Political Geography Scholars, at 11). See also Dahl (1956), Cain (1985), Campagna and Grofman (1990), Grofman (1983), Niemi and Fett (1986), Grofman, Koetzle, and Brunell (1997), McGann et al. (2015), and esp. Gelman and King (1990, 1994). I would note that the concept of partisan bias (and the complementary concept of partisan responsiveness in the form of the swing ratio) are first introduced in something close to their modern form in Tufte (1973), but similar ideas can be found in earlier statistical work as far back as the 1940s (see esp. Kendall and Yule 1950).

${ }^{38}$ The efficiency gap (McGhee 2014, 2017; Stephanopoulos and McGhee 2015) has also been proposed as a measure of partisan gerrymandering effects. Evidence about it was presented in Whitford v. Gill and Common Cause v. Rucho, as well as in League of Women Voters v. Pennsylvania. I have not made the efficiency gap one of my proposed metrics, since both advocates and proponents of its use in gerrymandering cases agree that it measures something distinct from partisan asymmetry/partisan bias a la Tufte (1973). I should also note that, though the measure was favorably referenced, I do not believe that the expert witness testimony presented about the efficiency gap in cases such as Gill and Rucho was critical to the findings for plaintiffs in these cases, since each case had other types of evidence presented about measures of disparate partisan impact. 
statewide vote, would not receive approximately $70 \%$ of the seats, bias is present. ${ }^{39}$

Another simple measure of partisan asymmetry is the mean minus median gap, which has "welldefined mathematical properties." 40 It compares each party's actual vote share in the median district to its average actual vote share across all districts. If a party's median vote share is lower than its average vote share, asymmetry is at work. This is because "[b]y packing opposing voters into a small number of districts, the gerrymandering party holds down the targeted party's vote shares in many districts, which depresses the target party's median vote share, even while its average (mean) vote share is unchanged." ${ }^{11}$ This metric is highly manageable for courts: "It focuses on two observable numerical facts" - the mean and the median- "and subtracts one from the other." ${ }^{42}$ Like the more sophisticated measures of partisan bias, the mean-median gap has well-established tests for statistical significance to assess the role of chance in generating observed differences. ${ }^{43}$

There are more complex models of partisan bias available that, for example, draw on data from the entire shape of the seats-votes curve, do not assume uniform vote shifts across all districts, take into account incumbency factors, and generate measures of statistical significance-i.e., how confident we are that the observed bias is not due to chance. Such measures also distinguish between partisan bias and what is called swing ratio, the slope of a seatsvotes curve. And we would expect such measures to be presented by experts in cases challenging partisan gerrymandering. But exploration of these more sophisticated measures is beyond the scope of the present essay. ${ }^{44}$ Suffice it to note that these models are well established in the political science literature, less complex in their mathematical underpinnings than methods regularly used in racial gerrymandering cases (such as Gary King's 1997 model of ecological inference), and would easily pass a Daubert test. ${ }^{45}$

That there are multiple metrics available is a feature, not a flaw, reflecting the cumulative process of building scientific knowledge. ${ }^{46}$ The metrics are fundamentally complementary. Some are more complex in their calculations than others, but they all seek to measure the same thing: the magnitude of the disparate burden (if any) that a challenged map imposes on a political party and its supporters. ${ }^{47}$

\footnotetext{
${ }^{39}$ Alternatively we could add just add three percentage points to party A's vote share in each district to bring up Part A's vote share from $47 \%$ to $50 \%$ and subtract three percentage points from party B's vote share in each district to bring down Part B's vote share from $53 \%$ to $50 \%$ and check to see if each party now receives $50 \%$ of the seats. If not, there is a bias in favor of one of the parties. Of course, such a bias might be explicable by geographic factors or due to chance, or it may only be temporary. Ruling out such possibilities is why we need a multi-pronged test. And, as noted below, there are more sophisticated approaches to assessing partisan bias that provide greater reliability. But the use of simple methods can allow a court an intuitive check on the plausibility of expert witness testimony using more sophisticated methods.

${ }^{40}$ Wang (2016b, 372); see also Wang (2016a).

${ }^{41}$ Amicus Br. of Samuel S. Wang, Harris v. Ariz. Indep. Redistricting Comm'n, No. 14-232 (U.S.Nov. 2, 2015), at 4.

${ }^{42}$ McDonald and Best (2015).

${ }^{43}$ Wang (2016b, 372).

${ }^{44}$ See Gelman and King $(1990,1994)$ and discussion in Grofman and King (2007, 10-13).

${ }^{45}$ Daubert v. Merrell Dow Pharmaceuticals, 509 U.S. 579 (1993). The Rucho court slip opinion at pp. 65-74 identifies numerous examples in which courts have relied on statistical evidence. It notes (p.74): “Advances in statistical and empirical theory and application, therefore, have the potential to allow parties, experts, and amici to provide courts with more rigorous and probative evidence, thereby decreasing the risk that courts will render a decision that later proves to have rested on an errant empirical analysis. Consequently, it makes no practical or
}

legal sense for courts to close their eyes to new scientific or statistical methods." (Also see discussion in Rucho, pp. 75-76, of the probative power of multipart evidence.)

${ }^{46} \mathrm{An}$ analogy from another domain of voting rights case law is pertinent. If we look at a term of art such as racially polarized voting, whose determination is critical in most racial vote dilution and racial gerrymandering cases, it turns out that there are multiple ways we might measure the level of racial polarization in a given jurisdiction, including homogeneous precinct analysis (Loewen 1982), ecological regression (Grofman, Migalski, and Noviello 1985), and ecological inference (King 1997). The latest of these methods, ecological inference, has the best statistical properties, but rests on much more mathematically complex foundations. Yet, when voting is clearly racially polarized, when the appropriate data needed by each method is available, in the hands of competent experts it really does not matter much which of these methods is used (Cf. Grofman 2000).

${ }^{47}$ As Gary King (personal communication, 2016) noted in comments on an earlier version of this essay, when it comes to partisan asymmetry: "You can say that some methods are more sophisticated and thus give considerably more precision and less error; others may be more intuitive in how they are calculated; others are just different ways of doing the same thing; still others do the same thing but present concepts in different ways that may be useful to understand from yet other perspectives. We know more about how to estimate partisan bias than we ever have, and the Justices can be confident that improvements will continue, and no massive changes in the estimates will come from this process." 


\section{Providing evidence that effects will be durable}

The second element, lack of responsiveness, perhaps better referred to as durability of effects, is distinct from partisan bias. Partisan bias can be high and yet fleeting, or it can be low and yet long lasting. Looking at the expected duration of partisan effects allows us to screen out cases where the political process can provide a remedy. The responsiveness element asks whether the party out of power can alter its fate by persuading voters to support it in future elections-i.e., whether a disparate partisan impact will endure throughout the decade following redistricting or even beyond. If a map is responsive, then when voters change their allegiances, their representation also changes, making judicial intervention unnecessary.

If a map is not responsive, then citizens' votes at the polls do not affect electoral outcomes, showing that the politicians have chosen the voters, and not the other way around. In that circumstance, we can expect partisan asymmetry to endure. When district lines freeze outcomes in favor of one political view, opposition voters can be effectively "shut out" of the political process. ${ }^{48}$ Requiring that plaintiffs demonstrate that the map is not responsive to changes in voter preferences ensures that courts do not intervene in the political process where it can function properly. If a map does not persistently obstruct competition, voters' remedy lies at the polls, not in the courts.

The methods to demonstrate likely durability are quite straightforward. They require experts to take historical levels of electoral tides into account and project the magnitude of previous inter-election vote share shifts into the present districts. In so doing, we can estimate the range of realistically possible election outcomes. With responsiveness, as with partisan bias, while experts have access to very sophisticated prediction models, there are some straightforward ways that courts can use to assess expert witness testimony about likely changes in outcomes. There are two simple questions for courts to ask. What is the proportion of districts that are competitive? And, if inter-election shifts in vote shares (electoral tides) are at their historical levels, in what proportion of the districts can outcomes be expected to be stable? Responsiveness/durability is a function of the number of competitive seats in a map-the districts most likely to shift hands with electoral tides (Brady and Grofman 1991). Of course, when mul- tiple elections have occurred under the challenged map, there is little need to rely on experts to assess responsiveness. If vote shares have changed, but seat shares have not, the challenged map is showing a lack of responsiveness to electoral shifts.

As Justice O'Connor noted in Bandemer, some gerrymanders could potentially be "self-limiting," e.g., if map drawers "crack" voters across multiple districts to create margins of victory so thin that they evaporate in future elections. ${ }^{49}$ Grofman and Brunell (2005) look for evidences of "dummymanders" in southern congressional redistricting in the 1990 round of redistricting. A dummymander, a term coined by A Wuffle $^{50}$ is a plan drawn by one party that ends up favoring the opposite party due to changing electoral tides that were not anticipated in the line drawing. Grofman and Brunell find evidence of Democratic dummymandering in some Southern states. However, (a) there is good reason to believe that this phenomenon is very rare in the current era of sophisticated computer redistricting, and (b) present day social science tools allow us to detect "those cases in which a gerrymander ... [was] attempted but ... not very well done..." (Grofman and King 2007, 13).

There are two clear explanations for why durability of gerrymandered outcomes is higher than in earlier decades. First, the newest, computer-driven redistricting now allows map drawers to make very precise refinements to district lines down to the census-block level. With this sophisticated new technology, map drawers can fashion maps that eliminate meaningful competition for most districts. McGann et al. $(2016,87)$ note: “[A]rmed with modern geographical information system software and an absence of judicial constraints, it is possible to engineer so much advantage that [a map can] satisfy both ... goals" of "seat maximization and incumbent protection." Thus, generally speaking, gerrymandered victory margins are no longer so thin that they risk disappearing. ${ }^{51}$ Second,

\footnotetext{
${ }^{48}$ In an era of hyperpolarized politics, politicians are responsive to the views of their own partisans and not to the electorate as a whole. See, e.g., Br. of Bipartisan Group of 65 Current and Former State Legislators, Gill v. Whitford, No. 16-1161 (U.S. 2017), at 12-21.

${ }^{49} 478$ U.S. at 152.

${ }^{50}$ Personal communication (December 1994),

${ }^{51}$ See, e.g., Issacharoff and Nagler $(2007,1122)$ : “[D]espite relative overall national parity between the parties in the post-War period, the districts held by each party tend to be more firmly in their control than ever before."
} 
political polarization of the electorate is increasing. ${ }^{52}$ With fewer swing voters, there is less risk of a victory margin eroding over time.

\section{Ruling out electoral geography and chance as explanations for the disparate impact}

The approach that is most directly linked to the definition of partisan gerrymandering given at the beginning of this article requires us to look at a large number of computer generated "randomly drawn" plans that generate the requisite number of contiguous districts. Such plans would be generated using units of aggregation such as voting precincts or elements of census geography such as blocks or tracts, and are based on the actual electoral geography. In addition to contiguity, the computer can also be programmed to seek to satisfy other of the set of what are often called "good government" criteria (see, e.g., Grofman 1985, Table 3) that put constraints on districting. ${ }^{53}$ These include criteria such as the one person, one vote standard, respect for political subunit boundaries, and compactness-as variously measured (Niemi et al. 1990). The computer can assess the extent to which each of these computergenerated plans satisfies the given criterion, and can also can assess information that would be relevant to determining whether the plan violated Section 2 of the Voting Rights Act or the Fourteenth Amendment. ${ }^{54}$ The next step is to compare the expected/projected partisan outcomes in the actual plan with the distribution of partisan outcomes in the randomly drawn plans. But the relevant comparison is not with the totality of such plans, but only with the subset of such plans that equal or surpass the challenged plan with respect to the satisfaction of the constitutional and statutory criteria that are deemed legally relevant. ${ }^{55}$

By restricting ourselves to plans that are at least as good in good government terms as the challenged plan, we have a direct way to implement the idea that gerrymandering is to be judged relative to a baseline of what is actually feasible. ${ }^{56}$ If we generate a frequency distribution of expected partisan outcomes in such comparable plans, based on outcomes in previous elections projected into the new districts, then we can compare that distribution to the actual (or projected) seat distribution in the challenged plan. If the partisan outcomes in the challenged plan are far away from what would be expected in this subset of computer-drawn plans, using standard statistical criteria such as the two or three standard deviations test set that is widely accepted in both the statistical and legal literature (see esp. Castenada v. Partida ${ }^{57}$; see also Bazemore

${ }^{52}$ See, e.g., Pew Research Center, Political Polarization in the
American Public, available at <https://tinyurl.com/p4scahz>
(last updated June 12, 2014) ("Republicans and Democrats are
more divided along ideological lines-and partisan antipathy is
deeper and more extensive - than at any point in the last two decades.”).

${ }^{53}$ A more current inventory of state provisions is found in Justin Levitt, "Where Are the Lines Drawn?" in his blog, All About Redistricting, <https://tinyurl.com/aw3qgn5> (last visited Aug. 10, 2017). Grofman (2015) provides a list of the criteria that are commonly thought to fall into the "good government" category and a brief discussion of tradeoffs among them in the context of Virginia congressional redistricting.

${ }^{54}$ Such criteria have been embedded in state constitutions in states such as California or Florida that have, in the past decade or so, passed initiatives affecting redistricting practices, and some are found in other state constitutions (see Grofman 1985, Table). They are also found enumerated in court cases where courts have drawn redistricting plans of their own in situations where they have been forced to do so by the failure of states to remedy an unconstitutional districting in a timely fashion (see e.g., Grofman 2015).

${ }^{55}$ However, another way in which a computer simulation of alternative plans can be relevant is by using it to show that, when the computer is instructed to take good government criteria into account, the plans that result satisfy those good government criteria (e.g., splitting of subunit boundaries) to a far greater extent, on average, than does the challenged plan. Thus, the challenged plan cannot be justified by a claim that the partisan advantages it creates were required by attentiveness to neutral and legitimate factors.

${ }^{56}$ Because we are using the results of neutrally drawn plans based on geography as our baseline for comparison, we are implicitly allowing for biases in partisan outcome that may arise from differential geographic concentration of partisan voting strength. Whether such geographically induced biases should be addressed in the remedy if a plan has been held to be unconstitutional we regard as entirely a legal question that remains to be resolved by courts. By analogy with the racial gerrymandering cases the answer could be yes, in that packing of racial populations are treated as a potential constitutional violation when that packing is intentional and is "unnecessary" for the purposes of providing the protected group an "equal opportunity to elect candidates of choice." Compliance with supposed neutral criteria may lead to inadvertent advantages to one party. There is some evidence that "political groups that tend to cluster (as is the case with Democratic voters in cities) [c]ould be systematically affected by what might be called a 'natural' packing effect," Vieth, 541 U.S. at 290 (plurality)—although new empirical evidence indicates that this effect has been overstated. McGann et al. $(2016,135)$ assert: "[G]eographic and demographic constraints (such as the urban concentration of Democratic voters, the requirement to draw majority-minority districts, and the geographic sorting of voters) cannot account for the level of partisan bias we observe, and certainly cannot account for the increase in bias we observe between the 2000 and 2010 districting rounds."

${ }^{57} 430$ U.S. 482 (1977). 
v. Friday ${ }^{58}$ ), then we have direct evidence that the disparate partisan impact in the challenged plan was not due to the electoral geography in the jurisdiction or to chance.

Due to "advance[s]" in the "field of information technology," 59 vastly improved computing power permits experts to create hundreds (or even millions) of computer-generated alternative maps. These computer-generated maps enable experts to identify the precise quantum of disparate treatment that is "man-made" - the product of deliberate efforts of the party in power to penalize the oppositionas distinct from the level of disparity that may be produced by the effects of ordinary districting practices, concern to avoid racial vote dilution, voters' residential patterns, or chance. The work of Chen and Rodden $(2013,2015)$ illustrates the methodology of computer based simulations of redistricting maps, ${ }^{60}$ as does that of Cho and Liu (2016) and Cain et al. (2018). Both Professor Chen and Professor Cho have provided expert witness testimony in recent partisan gerrymandering court cases, and similar methodology was used by Professor Jonathan Mattingly, who provided testimony in Rucho. ${ }^{61}$

\section{Feasible remedy}

Without a feasible remedy, there cannot be a cause for action. Thus, I am inclined to think that the burden is on plaintiffs to offer to the court a plan that both remedies the injury and satisfies constitutional and statutory standards to at least the same degree as the challenged plan. That plan may not be the plan that the court adopts, and the court may choose to defer to the legislature in redrawing lines to deal with the constitutional violation found, but there must be evidence that a remedy is possible. However, in the present absence of a decision by courts laying down clear standards for what counts as a violation, it seems reasonable to allow plaintiffs to defer the offering of a remedy until after the finding of a constitutional violation.

Once a plan has been held to be an unconstitutional partisan gerrymander, on the one hand, plaintiffs might offer proposals for remedy that may actually tilt the partisan bias in the other direction, while, on the other hand, when legislators are given a second bite at the apple, legislators with partisan motivations will seek to minimize the partisan consequence of the changes that they propose and/or only make cosmetic changes. From a social science perspective the most important question about remedy is how far-reaching it needs to be. Courts are going to have to be attentive to how much change in a plan found unconstitutional will be required. For example, if the estimated partisan advantage to one party had been four seats, is a proposed remedy plan reducing that estimated advantage to three seats adequate?

Here social science evidence can be very relevant. If evidence has been presented using computer simulations of alternative plans and their expected partisan effects, such computer simulations can help courts assess the range of expected outcomes under a neutral line drawing process. ${ }^{62}$ Also, some of the computer-generated plans whose partisan outcomes are not as extreme as the challenged plan may, themselves, offer a feasible remedy. However, I do wish to issue one very important note of caution. The computer simulations I have seen often freeze existing majority-minority districts in place so as to guarantee that the computer-drawn plans cannot be faulted for racial vote dilution. But, racial gerrymandering that packs minority voters also packs Democratic-leaning voters normally to an even greater extent. Indeed, sometimes racial gerrymandering is simply a means to a partisan end. Thus, simulations that freeze existing majorityminority districts in place may inadvertently perpetuate a Republican gerrymander "inside" the simulated maps, and thus lead us to misestimate the expected distribution of partisan outcomes under supposedly neutral line drawing. ${ }^{63}$ In this way the results of the simulation would underestimate the extent to which

\footnotetext{
${ }^{58} 478$ U.S. 385, 398-402 (1986).

${ }^{59}$ Erfer v. Com, 794 A.2d 325, 333 (2002).

${ }^{60}$ See also Chen and Cottrell (2016).

${ }^{61}$ A rather different computer algorithm is discussed in Chikina, Frieze, and Pegden (2017). This algorithm has been used by Professor Pegden in expert witness testimony in League of Women Voters v. Pennsylvania about the results of his computer simulation of redistricting plans.

${ }^{62}$ Chen and Cottrell (2016).

${ }^{63}$ In some cases such unnecessarily packed majority-minority districts will be a heritage of plans drawn by Democrats in earlier decades, but the perpetuation of the packing in a Republican-drawn plan can nonetheless contribute to a gerrymander that harms Democrats as a class.
} 
the actual plan is a pro-Republican gerrymander. Moreover, in the remedy phase, failure to redraw districts that have minority populations well in excess of what is needed to provide minority communities with an equal opportunity to elect candidates of choice will simply perpetuate partisan gerrymandering effects.

Sometimes, courts may have to craft the remedy themselves, perhaps via the appointment of a Special Master. Partisan gerrymandering, as defined above, is a feature of a plan as a whole, but is achieved by devices such as packing and cracking in particular districts. ${ }^{64} \mathrm{My}$ own experience in line drawing suggests strongly that remedying partisan gerrymandering might be done by seeking to adjust boundaries in a relatively limited number of districts, namely, those where the cracking and/or packing have been most extreme. Of course, in remedying packing or cracking in any given district, of necessity there will be changes that "ripple" to affect adjacent districts. While the ripple effects of changes to remedy constitutional violations can be limited, ${ }^{65}$ it is a legal issue about the extent to which any deference must be paid to a plan that overall is so tainted by partisan bias that we could describe it as originating from what we might call "partisan lust," especially when such plans violate good government criteria to an extent that would be inappropriate in a court-drawn plan. In particular, it is a legal issue not yet resolved by courts as to the extent to which any deference must be paid to incumbency protection in such egregious partisan gerrymanders, since the achievement of incumbent status is so inexorably tainted by the partisan nature of the map.

\section{Ascertaining intent}

In Davis v. Bandemer, when it declared partisan gerrymandering to be in principle justiciable, the Supreme Court majority downplayed the importance of intent in determining whether or not a plan was a partisan gerrymander. The Court majority thought that intent to engage in partisan maximizing could be more or less taken for granted as a motivation if the control of the redistricting process (and control of the governorship in states where the governor possessed veto power over redistricting plans) was unified in the hands of a single party. ${ }^{66}$ But, in the subsequent Shaw v. Reno ${ }^{67}$ line of jurisprudence, courts are forced to draw con- clusions about preponderant motive, and, under cases such as Easley v. Cromartie, ${ }^{68}$ it has become necessary for courts to distinguish partisan intent from racial intent. Thus, it seems as if intent may well remain a necessary element of any trial on the merits of a partisan gerrymandering claim and it, indeed, plays a key role in recent partisan gerrymandering challenges.

We have focused here on aiding courts in understanding the social science tools for isolating disparate partisan effects since, if the disparate burden on voters cannot be explained by neutral factors, or compelling state purposes, or chance, then intentional partisan gerrymandering can be inferred. ${ }^{69}$ This is not, however, to say that non-statistical evidence of intent is irrelevant. For example, even setting aside questions of legislative privileges, legislators' publicly available statements can be evidence of an intent to maximize partisan advantage. So, too, can analyses of the shifting of blocs of voters between districts to "pack" or "crack" particular groups, or the disparate treatment of incumbents. ${ }^{70}$ Deviations from the

${ }^{64}$ The two basic gerrymandering techniques for single-seat plurality elections (Grofman 1985) are dispersal of minority voting strength (cracking) and concentration of minority voting strength (packing). See also Owen and Grofman (1988).

${ }^{65}$ For example in Personhuballah v. Alcorn, a case that involved race-related gerrymandering in Virginia's 3rd congressional district (CD3), the court-imposed remedy for a Shaw-type violation necessarily made changes that impacted not just CD3 but also the four districts that immediately touched CD3. Thus the remedy affected five districts, not just one. However, the changes were minimal in three of the four districts that bordered $\mathrm{CD} 3$, and six of the eleven congressional districts in the state were left completely untouched (Grofman 2015).

${ }^{66}$ One Supreme Court justice suggested in the oral argument in Gill that we require unified control before a partisan gerrymandering challenge can be brought, since without unified partisan control the majority party may find itself unable to pass an egregious partisan plan or may see it vetoed by a governor of the opposite party.

${ }^{67} 509$ U.S. 630 (1993).

${ }^{68} 532$ U.S. 234 (2001).

${ }^{69}$ Cf. Bazemore v. Friday, 478 U.S. 385, 398-402 (1986) (using statistical analysis in Title VII case to rule out potential neutral reasons for racial disparities in salaries).

70 "Hijacking" pairs incumbents of the same party in one district, ensuring that one will not be reelected. "Kidnapping" removes a disfavored incumbent's core supporters from her district, reducing her chances of reelection. "Redistricting, a Devil's Dictionary," ProPublica (Nov. 2, 2011), <https://tinyurl .com/y9uuagw8 $>$. I believe that A Wuffle is responsible for the coining of the term "kidnapping." Ceteris paribus, incumbents generally garner more votes than other members of the same party running in the same district (King and Gelman 1991). 
ordinary legislative process, such as secrecy, limited debate, or party-line voting ${ }^{71}$ in the enactment of the map are also clearly relevant. And although invidious partisan gerrymanders can look visually "pretty" while still maximizing partisan advantage, contorted district lines and disregard for traditional districting criteria, even if not themselves illegal, are surefire signals that some form of gerrymandering is afoot.

\section{LEGAL AND EVIDENTIARY ISSUES}

\section{New types of expert witness testimony critical to a holding of unconstitutional gerrymandering}

In past work, I have argued that a standard for unconstitutional partisan gerrymandering should be based on the severity of partisan asymmetry. The five justices who referenced partisan asymmetry in their opinions in LULAC (based largely on the discussion of that method in an amicus brief in the case by Gary King, Bernard Grofman, and others) asserted that partisan asymmetry should be a component of any test for unconstitutional partisan gerrymandering, but they also made it clear that, standing alone, it is not enough. ${ }^{72}$ As should be apparent from the discussion above, now, with the hindsight/insight gained in the more than a decade since that amicus, I fully agree with that conclusion. In my view, proof of partisan asymmetry is not sufficient, but it is definitely necessary.

Here I have argued that, in addition to partisan asymmetry, a test for unconstitutional partisan gerrymandering also should include evidence about the expected durability of partisan bias, and evidence that allows us to rule out geographic and chance factors as explanations for the observed/ projected disparate impact; i.e., it should require evidence of causation. In the previous sections I have identified social science tools that address each of these issues: measures of partisan bias to determine the severity of disparate impact in the challenged plan; use of data on past inter-election electoral tides and data on district level competitiveness in the challenged plan to assess the likely durability of the plan's partisan effects; and computer simulations of "randomly drawn" alternative plans to see how likely we would have found the extreme partisan outcomes observed in the challenged plan in plans that are just as good as the challenged plan with respect to traditional districting criteria.
In the course of rejecting the plaintiffs' claims in Bandemer, Vieth, and LULAC, there are strong signs that a potential majority of the Court would agree that partisan asymmetry, lack of responsiveness, and causation are essential to a finding of unconstitutional partisan gerrymandering. ${ }^{73}$ But testimony in Bandemer, Vieth, and LULAC did not offer evidence of all three of these critical elements. Indeed, Bandemer had none of them, ${ }^{74}$ and in the other two cases there was not clear evidence about more than one of the elements. ${ }^{75}$ Furthermore, in all three cases, plaintiffs failed to offer to the court a legal standard that incorporated

${ }^{71}$ The absence of strict party-line voting should be viewed in context. Some incumbent members of the disadvantaged party may have incentives to support a districting plan that affords them (or friends on their side of the aisle) a safe legislative or congressional seat, or that creates a congressional seat that they might run for in the future.

${ }^{72}$ Justice Stevens, joined by Justice Breyer, identified partisan asymmetry as "a helpful (though certainly not talismanic) tool," provided one recognizes that "asymmetry alone is not a reliable measure of unconstitutional partisanship." Justice Kennedy, joined by Justices Souter and Ginsburg, suggested that the standard would be applied only after at least one election has been held under the redistricting plan at issue.

73 " $[\mathrm{U}]$ nconstitutional acts of partisan gerrymandering must do what appellants' sole-motivation theory disavows: show a burden, as measured by a reliable standard, on the complainants' representational rights" (LULAC, 548 U.S. at 418); plaintiffs failed to establish a standard under which they were entitled to a majority of the seats, and they failed to rule out "natural" causes of packing (Vieth, 541 U.S. at 289-90 (plurality)); plaintiffs' claims failed because proportionality is not required and because "more than a showing of possibly transitory results" is required (Bandemer, 478 U.S. at 129-130, 140).

${ }^{74}$ The primary evidence in Bandemer was that a single election had yielded slightly disproportionate results. 478 U.S. at 134 (plurality). The Bandemer plaintiffs offered no evidence of partisan asymmetry, lack of responsiveness, or causation. Instead of partisan asymmetry, they offered proportionality as their standard. But as Indiana's expert witness in that case pointed out, it is "totally fallacious ... that a discrepancy between vote share and seat share of more than a few percentage points is proof of intentional gerrymandering." (Grofman 1985, 120). Nor did the plaintiffs in Bandemer offer any evidence of lack of responsiveness, leaving unrebutted the State's contention that if the plaintiffs won even an "additional few percentage points ..., they would have obtained a majority ... in both houses." Bandemer, 478 U.S. at 135 (plurality). Finally, plaintiffs failed to prove causation because their test left unaddressed the potential for discrepancies in treatment caused merely by "natural advantages." (Grofman 1985, at 120). See also Grofman (1982).

${ }^{75}$ Of course, the fact that technology of computer-simulated plans has only recently developed to the point of being able to readily create compelling evidence on the causality prong is an obvious reason why no such evidence was offered in partisan gerrymandering cases previous to the present decade. 
all three elements. Indeed, no plaintiffs came even close. ${ }^{76}$ Thus, despite some 30 years of partisan gerrymandering redistricting litigation, courts can come afresh to the issue of crafting a judicial standard, using a well-defined multi-pronged test, without having to worry about whether such a standard conflicts with past precedents.

In this context, I would point out that Whitford is the first case before the Supreme Court in which the trial record offered evidence of each of the first three necessary elements (asymmetry, durability, and causation), as well as evidence on intent and remedy. Moreover, I also find such evidence on all five elements in the trial record in Common Cause v. Rucho. And I believe it is also present in the trial record of League of Women Voters v. Pennsylvania. Of course, that evidence on each of these points was provided in each of these cases is not the same thing as saying that the evidence provided was complete and reliable or that it was strong enough to support a finding of a constitutional violation. ${ }^{77}$ Let me also again emphasize that elements such as asymmetry, durability, and causation are distinct. One can have partisan bias that is severe but not durable, or durable but not intended, or intended but not durable, etc. In my view, each of the five prongs proposed above must be separately shown to hold.

\section{Moving from the identification of required elements to the specification of a legal standard: An incremental approach}

I propose to distinguish metrics from standards. Metrics for partisan gerrymander tell us what electoral features to measure; standards tell us when the measurements provided by expert witnesses about these various plan features take us from "politics as usual" to unconstitutionality. Metrics tend to come from the social sciences; standards tend to come from courts. Above, we have identified wellestablished social science methods that will allow us to rather precisely specify metrics for disparate impact, and durability, and a straightforward way to use computer simulations to assess causation.

I propose that courts craft a standard for unconstitutional partisan gerrymandering that draws on these metrics in ways that parallel how courts have dealt with metrics provided by social scientists in other voting rights contexts, such as one person, one vote and racial vote dilution. While no single number tells it all, the five-pronged approach identifies the numerical, geographic, and historical information that is needed-evidence that can straightforwardly be presented by experts and readily evaluated by courts. In situations where legislatures are doing the line drawing, politics will always play a role in the establishment of congressional and legislative boundaries, but we need also ask whether those considerations, "though generally permissible, were applied in an invidious manner or in a way unrelated to any legitimate legislative objective." ${ }^{78}$ In other words, did "politics" go "too far" in infringing upon fundamental associational and representational rights?

${ }^{76}$ In Vieth, the plaintiffs took a somewhat different tack than the plaintiffs in Bandemer. They argued for a two-pronged test: (1) a predominant intent to achieve partisan advantage, shown through the subordination of neutral and legitimate criteria; and (2) a "totality of the circumstances" determination that the map would have the effects of "thwart[ing] the plaintiffs' ability to translate a majority of votes into a majority of seats" (Vieth, 541 U.S. at 284-87 (plurality)).The effects prong of this test focused on the wrong criteria: it claimed that a party that won the majority of votes was entitled to a majority of seats, without establishing any differential treatment of voters based on their political views and associations. The case was decided on a motion to dismiss, and because no election had taken place under the challenged plan, the plaintiffs' claim of adverse effects rested solely on an allegation that, in the future, they would be deprived of a majority of Pennsylvania's congressional seats, despite achieving a majority of the statewide vote. $I d$. at $272-73,287$. The plurality asserted that the effects claim reduced to a claim of proportional representation, similar to the proportionality test rejected in Bandemer. Id. at 288. And of course, there was no evidence of durability or causation offered. In $L U L A C$, the district court did hear limited expert evidence regarding partisan asymmetry that examined how many seats each party would win if, hypothetically, each obtained $50 \%$ of the statewide vote (548 U.S. at 466-68, Stevens, J., concurring in part and dissenting in part). But, plaintiffs abandoned this evidence by the time they got to the Supreme Court. Instead, their theory of the case was that the sole motive for the Texas legislature's decision to engage in mid-decennial redistricting was to reap partisan advantage. Id. at 416-17 (opinion of Kennedy, J.). In other words, plaintiffs' theory depended only on intent. In fact, plaintiffs argued that "courts need not inquire about, nor parties prove, the discriminatory effects of partisan gerrymandering. Id. at 417 (emphasis added).

${ }^{77}$ While I will not discuss the specific expert witness conclusions, what cannot be disputed is that the evidence presented at trial in these cases involved multiple experts and a multicomponented approach that reflects advances in social science knowledge that have occurred in the decade since $L U L A C$ about how to measure gerrymandering, as well as incorporates technological advances in our ability to use the computer to generate alternative plans.

${ }^{78}$ Vieth, 541 U.S. at 307 (Kennedy, J., concurring). 
The available social science tools are well suited to be used to specify what counts as a violation and what counts as a remedy. Regarding violation, for example, courts could require the plaintiffs to establish that at least one seat now lost to partisan gerrymandering could have a different partisan outcome in a remedial plan satisfying traditional redistricting criteria to the same or greater extent than the challenged plan. ${ }^{79}$ Such an approach is consistent with the Supreme Court's approach in Section 2 voting rights challenges, where the third prong of the Thornburg v. Gingles ${ }^{80}$ test requires plaintiffs to demonstrate that a remedial plan would provide at least one additional single-member district with a geographically compact minority population large enough to address the voting rights violation found. ${ }^{81}$ In this context I note that (a) most measures of asymmetry can be translated into a percentage or number of seats in a plan affected by partisan bias, and (b) computer simulations using projected elections allow for estimating partisan impact in terms of expectations about partisan seat balance. Alternatively, regarding the amount of disparate impact needed to distinguish lawful politics as usual from unconstitutional egregious partisan gerrymandering, the Court could use historical data to identify a threshold amount of bias that is atypical or egregious (Cf. Brown v. Thomson: "Our [one-person-one-vote] decisions have established ... that a [state legislative] apportionment plan with a maximum population deviation under $10 \%$ falls within this category of minor deviations" that are generally not actionable ${ }^{82}$ ).

Similarly, if we look to specifying what is needed to find a violation, for causation, courts might rely on jurisprudence in other civil rights arenas that look to evidence of statistical patterns that are two or more standard deviations outside the norm. And, when we look to evidence of durability, we can assess the likelihood that an existing partisan balance would be perpetuated based on projections using historical patterns of electoral tides and evidence on levels of competitiveness in the present districts. Finally, regarding intent, courts already regularly assess intent in a variety of constitutional and statutory settings and can readily examine the history of line drawing.

Of course, it is not enough to operationalize standards to identify unconstitutional partisan gerrymandering if these standards cannot be used to provide both internal and external judicial manageability. By external judicial manageability, I mean the development of an easy to apply litmus test to screen out frivolous partisan gerrymandering challenges in a way that will dramatically limit the cases that actually require a trial on the merits. By internal judicial manageability, I mean standards that have two important properties. First, they can be clearly and consistently applied to reach decisions. Second, they should be such that competent expert witnesses reviewing quantitative data will provide similar or near identical results, so that once courts have set legal thresholds, the legal conclusions from that statistical evidence will follow in a straightforward fashion.

One example of both external and internal manageability in voting rights jurisprudence is the threepronged test laid down in Thornburg $v$. Gingles. ${ }^{83}$ Its standard of multiple required elements screens out frivolous lawsuits, and the metrics it uses are precise enough and have well-developed statistical tools for their measurement that competent experts will make similar estimates.

The approach to partisan gerrymander advocated here, specifying necessary elements of any standard to be used to determine what constitutes an unconstitutional partisan gerrymander, could be used to generate a test for unconstitutional partisan gerrymandering inspired by the structure of (though largely substantively different from) the three-pronged test for vote dilution laid down in Thornburg v. Gingles. Like the Thornburg test, it is based on a set of necessary conditions and it proposes metrics that are well defined in the social science literature-ones whose measurement is something competent experts can provide. Thus, I believe it, too, satisfies both internal and external

\footnotetext{
${ }^{79}$ Courts may, however, wish to set a higher threshold for partisan gerrymandering cases than the Supreme Court did for racial gerrymandering cases. Also, the magnitude of the disparate impact threshold chosen might vary with the number of seats in the legislature or the congressional delegation at issue. ${ }^{80} 478$ U.S. 30 (1986).

${ }^{81}$ In Bartlett v. Strickland, 556 U.S. 1 (2009), in a plurality opinion, the Supreme Court tightened the Gingles standard by requiring an initial showing that there existed a remedy plan with at least one additional district in which the minority group constituted a majority of the citizen voting age population. However, districts with a lower minority population may yet be ones that present the minority community with an equal opportunity to elect candidates of choices. Moreover, the packing of minority populations to an unnecessary extent can also be evidence of racial gerrymandering and usually has partisan consequences as well.

${ }^{82} 462$ U.S. 835, 842 (1983).

${ }^{83} 478$ U.S. 30 (1986).
} 
criteria of manageability. Each of its parts (a) is relatively simple and can be explained intuitively in terms that any intelligent lay person could understand (especially with use of maps and graphs), ${ }^{84}$ (b) is conceptually distinct, (c) fits into a theoretical whole that satisfies our common sense understanding about what it is that we are trying to prove, and (d) has statistical elements that lend themselves to the eventual development of something like bright line legal thresholds. Moreover, rather than get into the rather murky domain of fairness, it offers criteria based on neutral treatment.

But once the courts have accepted concepts such as partisan asymmetry, durability, and causation as critical to a finding of unconstitutional gerrymandering, the Court need not adopt a mechanistic test, especially at the outset. Rather, the precise contours and evidentiary proofs required can be fleshed out on a case-by-case basis - with the benefit of insights gained from experience, the aid of competent experts, and the "crucible of adversarial testing on which [courts] usually depend." 85 Indeed, that is how the jurisprudence has evolved with respect to every other justiciable redistricting claim. ${ }^{86}$

For example, one-person-one-vote "jurisprudence, ... evolved through case-specific challenges." ${ }^{87}$ First, the U.S. Supreme Court held such claims justiciable in Baker v. Carr. ${ }^{88}$ Then, in Reynolds v. Sims, it announced "the two concepts of 'one person, one vote' and the 'equal population principle," ${ }^{89}$ — without specifying which of various proposed metrics would be used to evaluate compliance with that standard. ${ }^{90}$ Instead, it allowed "[l]ower courts [to] work out more concrete and specific standards for evaluating state legislative apportionment schemes in the context of actual litigation." 91 The standards and specific proofs required in Voting Rights Act and racial gerrymandering claims also evolved in the same incremental fashion-as they have in antidiscrimination law more broadly. ${ }^{92}$ In all of these contexts, experts developed multiple different metrics for analyzing whether the judicially pronounced standard was met; in none did courts pronounce at the very outset that a particular mathematical tool or threshold was required. ${ }^{93}$

\section{DISCUSSION}

There are three metrics derived from social science methods that we propose as critical to a finding of unconstitutional partisan gerrymandering: partisan asymmetry as a measure of disparate impact, effect durability, and statistical evidence based on simulated maps that can demonstrate that the observed partisan effects are not due to geographic or chance factors and the deviations from good government districting criteria could have been avoided. No one element is dispositive. Rather, each of these three discrete elements must be assessed separately. The first element, partisan asymmetry, considers whether and to what degree voters' representational rights have been burdened. The second, lack of responsiveness, considers whether the ordinary political process is able to provide a remedy. And the third, causation, ensures that disparate effects that can be explained as the result of neutral factors or of chance are not treated as unconstitutional. Rather, only invidious, intentional discrimination is actionable. Moreover, these

${ }^{84}$ Not only are the three concepts of partisan asymmetry, durability, and causation relatively intuitive, but the methods for measuring them more transparent than the statistical methods that courts routinely rely on in Voting Rights Act cases to infer how racial minorities vote. See generally Grofman (2000).

${ }^{85}$ Maslenjak v. United States, 137 S. Ct. 1918, 1931 (2017) (Gorsuch, J., concurring).

${ }^{86}$ The history of voting rights jurisprudence can largely be viewed as a movement from cases whose facts paint them as "horribles" to cases whose facts are such that the "correct" result is far less obvious. Litigation, by and large, leads to incremental change in the law, and greater specificity, but there can be tectonic shifts, as when something like a bright line test (such as the three prongs of Gingles) replaces or supplements a less precise test, such as one based on the "totality of the circumstances." (Grofman 1992).

${ }^{87}$ Holt v. 2011 Legislative Reapportionment Commission, 38 A.3d 711, 741 (Pa. 2012).

${ }^{88} 369$ U.S. 186 (1962).

${ }^{89}$ Holt, 38 A.3d at 740 (quoting Reynolds v. Sims, 377 U.S. 533 (1964)).

${ }^{90}$ In the one person, one vote, and racial vote dilution the history of litigation can be seen as taking us from decisions about metrics (e.g., total population deviation versus average population deviation versus minimum population needed to control a majority of the districts) to decisions about standards. In particular, over a set of cases, the Supreme Court clarified how the standard for "one person, one vote" compliance is different for state legislatures than for Congress.

${ }^{91}$ Reynolds, 377 U.S. at 578.

${ }^{92}$ See Br. of Heather Gerken et al., Gill v. Whitford, No. 161161 (U.S. 2017), at 8-12.

93 "Clear and compelling evidence" is the standard proposed by Judge Baylson in his dissenting opinion in the challenge to Pennsylvania's congressional districts, Agre v. Wolf (Case 2:17-cv-04392-MMB, E.D. Pa.; Document 213, filed Jan. 10, 2018; slip op. at p. 6), and while far from precise, such a standard might be a starting point if, in using it, courts were also to identify the concepts/metrics that specify the relevant evidence. 
metrics are not based on an abstract notion of fairness akin to a requirement that seat share equal the party's share of the overall vote. Rather they offer a standard of neutral treatment of the parties in allocating representational rights.

The ideas in this article are very closely related to the approaches taken in Whitford and in Rucho. What I have sought to do is to lay out, from a social science perspective, both the relevant metrics that were central to the empirical findings in these opinions and the relevant social science tools for estimating these metrics, so as to demonstrate manageability. If a multipronged standard for partisan gerrymandering were to be adopted based on the metrics and methods discussed in this essay, courts will be able to apply it coherently and consistently across cases, to distinguish and identify those egregious partisan gerrymanders that go above and beyond normal politics to invidiously target opposition voters for unequal treatment. ${ }^{94}$ I very much hope that courts will seize upon these ideas as a path out of the present morass. Otherwise, politicians will have every incentive to wield the technological advances in computerbased districting and statistical assessment of future electoral outcomes to craft ever more egregious partisan gerrymanders. Judicial abdication would ensure that officials are selected by the self-dealing maps they enact, rather than elected by the people they ostensibly serve-locking into place electoral advantages that are, for all practical purposes, impervious to changes by the electorate. ${ }^{95}$

\section{REFERENCES}

Brady, David W. and Bernard Grofman. 1991. "Modeling the Determinants of Swing Ratio and Bias in U.S. House Elections, 1850-1980." Political Geography Quarterly 10(3): 254-262.

Cain, Bruce E. 1985. "Assessing the Partisan Effects of Redistricting." American Political Science Review 79: 320-33.

Cain, Bruce E., Wendy K. Tam Cho, Yan Y. Liu, and Emily Zhang. 2018. "A Reasonable Bias Method for Redistricting: A New Tool for an Old Problem." William \& Mary Law Review 59(5).

Campagna, Janet and Bernard Grofman. 1990. "Party Control and Partisan Bias in 1980s Congressional Redistricting." Journal of Politics 52(4): 1242-1257.

Chen, Jowei and Jonathan Rodden. 2013. "Unintentional Gerrymandering: Political Geography and Electoral Bias in Legislatures." Quarterly Journal of Political Science 8: 239-269.

Chen, Jowei and Jonathan Rodden. 2015. "Cutting Through the Thicket: Redistricting Simulations and the Detection of
Partisan Gerrymanders." Election Law Journal 14(4): 331-345.

Chen, Jowei and David Cottrell. 2016. "Evaluating Partisan Gains from Congressional Gerrymandering: Using Computer Simulations to Estimate the Effect of Gerrymandering in the U.S. House." Electoral Studies 44: 329-340.

Chikina, Maria, Alan Frieze, and Wesley Pegden. 2017. "Assessing Significance in a Markov Chain without Mixing." Proceedings of the National Academy of Sciences of the United States of America 114(11): 2860-2864.

Cho, Wendy K. Tam and Yan Y. Liu. 2016. "Toward a Talismanic Redistricting Tool: A Fully Balanced Computational Method for Identifying Extreme Redistricting Plans." Election Law Journal 15(4):351-366.

Dahl, Robert A. 1956. A Preface to Democratic Theory. Chicago: University of Chicago Press.

Dixon, Robert. 1968. Democratic Representation: Reapportionment in Law and Politics. New York: Oxford University Press.

Gaddie, Keith. 2004. Expert Witness Report. Larios v. Cox, 1:03-CV-0693, United States Federal Court for the Northern District of Georgia, January.

Gelman, Andrew and Gary King. 1990. "Estimating the Electoral Consequences of Legislative Redistricting." Journal of the American Statistical Association 85(410): 274-282.

Gelman, Andrew and Gary King. 1994. "A Unified Method of Evaluating Electoral Systems and Redistricting Plans." American Journal of Political Science 38(2): 514-554.

Grofman, Bernard. 1982. "For Single Member Districts, Random Isn't Equal.” In Bernard Grofman, Arend Lijphart, Robert McKay, and Howard Scarrow (Eds.), Representation and Redistricting Issues. Lexington, MA: Lexington Books, 55-58.

\footnotetext{
${ }^{94}$ Any disparate burden on voters is measured relative to the baseline created by neutral factors (single-member, winnertake-all elections; compliance with constitutional requirements and the Voting Rights Act; the actual residential patterns of the electorate; map-drawing practicalities like contiguity and a respect for local subdivisions and communities of interests, and a preference for compact districts).

${ }^{95}$ Moreover, failing to deal with partisan gerrymandering will not substantially reduce the redistricting litigation coming to the courts. As long as they have no way to address egregious partisan gerrymandering, litigants will seek to address pernicious and likely to be durable partisan gerrymanders by bringing other sorts of challenges, including ones brought under a Shaw v. Reno standard. Until the Supreme Court grasps the nettle of specifying a test for unconstitutional partisan gerrymandering, present voting rights case law is flawed because it (a) allows legislators to claim intentional and even egregious partisan gerrymandering as their predominant motive as a way to escape racial gerrymandering claims under Shaw, thus forcing complex trials that hinge on accusations of racial motive; (b) allows line drawers to use racial gerrymandering to achieve partisan ends in such a fashion that, even if the racial gerrymandering is reduced by remedy brought about by a Shaw-type lawsuit, this may still leave untouched all or most of the partisan effects of the plan; and (c) there can be partisan effects of line drawing not tied to race, which will go legally unchallenged/unchallengeable.
} 
Grofman, Bernard. 1983. "Measures of Bias and Proportionality in Seats-Votes Relationships." Political Methodology 9: 295-327.

Grofman, Bernard. 1985. "Criteria for Districting: A Social Science Perspective.” UCLA Law Review 33(1): 77-184.

Grofman, Bernard. 1992. "Expert Witness Testimony and the Evolution of Voting Rights Case Law." In Bernard Grofman and Chandler Davidson (Eds.), Controversies in Minority Voting: The Voting Rights Act in Perspective. Washington, D.C.: Brookings Institution, 197-229.

Grofman, Bernard. 2000. "A Primer on Racial Bloc Voting Analysis." In Nathaniel Persily (Ed.), The Real Y2K Problem: Census 2000 Data and Redistricting Technology. New York: Brennan Center for Justice, New York University School of Law.

Grofman, Bernard. 2015. Report of the Special Master. Personhuballah v. Alcorn, Civil Action No. 3:13 cv678 (filed November 15).

Grofman, Bernard and Tom Brunell. 2005. "The Art of the Dummymander: The Impact of Recent Redistrictings on the Partisan Makeup of Southern House Seats." In Peter Galderisi (Ed.), Redistricting in the New Millennium. New York: Lexington Books, 183-199.

Grofman, Bernard and Keith Gaddie. 2017. Amicus Brief on Behalf of Neither Party in the U.S. Supreme Court. Gill v. Whitford, No. 16-1161 (U.S. 2017), filed August 19.

Grofman, Bernard and Keith Gaddie. 2018. Amicus Brief on Behalf of Neither Party in the Pennsylvania Supreme Court. League of Women Voters v. Pennsylvania (on Appeal from the Order of the Commonwealth Court of Pennsylvania), No. 261 MD 2017 (filed January 4.

Grofman, Bernard, William Koetzle, and Thomas Brunell. 1997. "An Integrated Perspective on the Three Potential Sources of Partisan Bias: Malapportionment, Turnout Differences, and the Geographic Distribution of Party Vote Shares." Electoral Studies 16(4): 457-470.

Grofman, Bernard and Gary King. 2007. "Partisan Symmetry and the Test for Gerrymandering Claims after LULAC v. Perry." Election Law Journal 6(1): 2-35.

Grofman, Bernard N., Michael Migalski, and Nicholas Noviello. 1985. "The 'Totality of Circumstances' Test in Section 2 of the 1982 Extension of the Voting Rights Act: A Social Science Perspective." Law and Policy 7(2): 209-223.

Hasen, Richard L. 2018 forthcoming. "Race or Party, Party as Race, or Party all the Time: Three Uneasy Approaches to Conjoined Polarization in Redistricting and Voting Cases." William \& Mary Law Review.

Issacharoff, Samuel and Jonathan Nagler. 2007. "Protected from Politics: Diminishing Margins of Electoral Competition in U.S. Congressional Elections." Ohio State Law Journal 68(4): 1121-1137.

Kendall, M.G. and A. Stuart. 1950. "The Law of the Cubic Proportion in Election Results." British Journal of Sociology 1(3): 183-196.

King, Gary. 1997. A Solution to the Ecological Inference Problem. Princeton, NJ: Princeton University Press.

King, Gary and Andrew Gelman. 1991. "Systemic Consequences of Incumbency Advantage in U.S. House Elections." American Journal of Political Science 35(1): 110-138.
Loewen, James. 1982. Social Science in the Courtroom. Lexington MA: Lexington Books.

McDonald, Michael D. and Robin Best. 2015. "Unfair Partisan Gerrymanders in Politics and Law: A Diagnostic Applied to Six Cases." Election Law Journal 14(4): 312-330.

McDonald, Michael P. 2004. "A Comparative Analysis of Redistricting Institutions the United States, 2001-02." State Politics and Policy Quarterly 4(4): 371-395.

McGann, Anthony J., C. Anthony Smith, Michael Latner, and Alex Keena. 2015. "A Discernable and Manageable Standard for Partisan Gerrymandering." Election Law Journal 14(4): 295-311.

McGann, Anthony J., C. Anthony Smith, Michael Latner, and Alex Keena. 2016. Gerrymandering in America: The House of Representatives, the Supreme Court, and the Future of Popular Sovereignty. New York: Cambridge University Press.

McGhee, Eric. 2014. "Measuring Partisan Bias in SingleMember District Electoral Systems.” Legislative Studies Quarterly 39(1): 55-85.

McGhee, Eric. 2017. "Measuring Efficiency in Redistricting." Election Law Journal 16(4): 1-26.

Miller, Peter and Bernard Grofman. 2013. "Redistricting Commission in the Western United States." University of California, Irvine Law Review 1(1): 637-668.

Niemi, Richard and Patrick Fett. 1986. "The Swing Ratio: An Explanation and Assessment. Legislative Studies Quarterly 11(1): 75-90.

Niemi, Richard G., Bernard Grofman, Carl Carlucci, and Thomas Hofeller. 1990. "Measuring Compactness and the Role of a Compactness Standard in a Test for Partisan and Racial Gerrymandering." Journal of Politics 52(4): 1155-1181.

Owen, Guillermo and Bernard Grofman. 1988. "Optimal Partisan Gerrymandering." Political Geography Quarterly 7(1): $5-22$.

Stephanopoulos, Nicholas and Eric McGhee. 2015. "Partisan Gerrymandering and the Efficiency Gap." University of Chicago Law Review 82(2): 831-900.

Tufte, Edward. 1973. "The Relationship between Seats and Votes in Two-Party Systems." American Political Science Review 67(2): 540-554.

Wang, Samuel. 2016a. "Three Tests for Practical Evaluation of Partisan Gerrymandering." Stanford Law Review 68: 12661318.

Wang, Samuel. 2016b. "Three Practical Tests for Gerrymandering: Application to Maryland and Wisconsin." Election Law Journal 15(4): 367-383.

Address correspondence to: Bernard Grofman Center for the Study of Democracy School of Social Sciences University of California, Irvine Irvine, CA 92697-5100

E-mail: BGTravel@uci.edu 